\title{
COMMENT
}

\section{When bigger is better}

\author{
Gregory A Petsko*
}

One of the side-effects of getting older is the constant feeling that things in general are just going to hell, and that everything was better when one was younger - a feeling that would consign one to permanent residence in Old Fogeyville, were it not so often accurate. Air travel really was better before deregulation. Telephone service was superior when a monopoly ran the phone company, and so on. If you want further proof that the good old days were indeed pretty good, you need only consider the recent proliferation of giant companies, formed by an epidemic of mergers and acquisitions that shows no signs of abating. Are a few enormous banks better than a bunch of smaller ones? The global financial crisis would suggest they are not. Can a handful of gigantic pharmaceutical companies turn out more drugs than, say, double the number of smaller ones? The pitiful number of new approved therapeutics would suggest that they actually may turn out fewer.

But there is one area where, I would claim, bigger may actually be better; where less is more. That is the area of scientific journals, where new titles sprout up like weeds and are about as welcome. There are a lot of things I didn't ask for that I seem to get anyway - grey hair; creaky joints; Republican senators, to name but a few - but high on my list are more journals. It isn't just that they add to the burden of keeping up with the literature, or that they tend, for the most part, to be of lower quality than their older brethren. The real problem is that they represent exactly the sort of thing we shouldn't be encouraging in modern biology: increasing specialization and niche-building.

Whatever possesses people that they suddenly believe that what the world needs is another specialty journal? Are they having that much trouble getting their own papers published? Do they long for the prestige of seeing 'Editor' next to their name, with all the fame, money, and attention from the opposite sex that it never brings? I think it's actually something else: a belief that a particular field isn't important unless it has a journal of its own - a misguided notion that, carried to the extreme (which is the only way things seem to get carried these days), leads to a journal for every sub-field, and sub-sub-field, and so on.

*Correspondence: petsko@brandeis.edu

Rosenstiel Basic Medical Sciences Research Center, Brandeis University, Waltham, MA 02454-9110, USA
Don't get me wrong: I am all in favor of the excellent trade journals that publish the bulk of the work in most areas of biology. But do we really need more? Should the height of our ambition really be to have our papers published by a journal that is seen by fewer people, and most of them our friends at that? If you think about it, don't we really need fewer specialty journals and more general journals?

Think of the places that people long to get their work published in; aren't all of them pretty general in their coverage of biology (or science as a whole)? Isn't the whole point of being published in such places that a great many people from a variety of fields will see the work and, ipso facto, it must be important? We can argue about the excessive influence that those journals have on the careers of scientists, especially young ones, but clearly there aren't enough of them to publish the many papers that clearly belong there. And wouldn't more general journals help break the hegemony of the existing ones? Of course, more general journals means more journals, and we've already decided that's a bad idea, right? So what's the answer?

The journal in which you're reading this is a fusion of BMC Biology with Journal of Biology. Think about it: where once there were two journals, now there is one, with expanded scope and a wider audience than either of its component parts. Isn't that exactly what we need? More mergers may be a bad idea for banks and drug companies, but it's a great idea for scientific publishing. And as journals transition from print + on-line to all on-line, a trend that is coming fast, it becomes easier to combine them and refocus them with minimal cost and disruption.

So all hail the new BMC Biology. Bigger, better, and broader, it represents what I fervently hope is the next trend in scientific publishing: the concatenation of more specialized publications into more general ones. For in the age of genomics, and systems biology, and more research aimed at human diseases, we need to think and read as broadly as we can. And we need journals that reflect that. Why not get them by combining smaller ones? After all, sometimes bigger IS better. And the future isn't always worse than the past. Not always.

Published: 12 April 2010

doi:10.1186/1741-7007-8-43

Cite this article as: Petsko GA: When bigger is better. BMC Biology 2010, 8:43 